\title{
Cultures of Silence and Cultures of Voice: The Role of Whistleblowing in Healthcare Organisations
}

\author{
Russell Mannion ${ }^{1 *}$, Huw TO Davies ${ }^{2}$ \\ Abstract \\ 'Whistleblowing' has come to increased prominence in many health systems as a means of identifying and \\ addressing quality and safety issues. But whistleblowing - and the reactions to it - have many complex and \\ ambiguous aspects that need to be considered as part of the broader (organisational) cultural dynamics of \\ healthcare institutions. \\ Keywords: Whistleblowing, Healthcare Organizations, Cultures of Silence, Cultures of Voice, Safer Care \\ Copyright: @ 2015 by Kerman University of Medical Sciences \\ Citation: Mannion R, Davies HT. Cultures of silence and cultures of voice: the role of whistleblowing in \\ healthcare organisations. Int J Health Policy Manag. 2015;4(8):503-505. doi:10.15171/ijhpm.2015.120
}

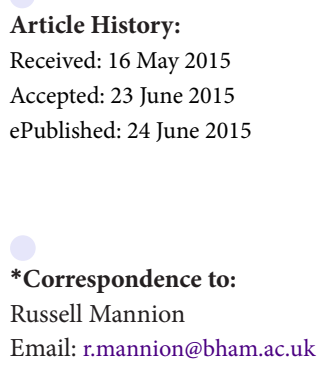

Speaking Truth to Power?

Healthcare scandals in many countries have demonstrated that uncaring and ineffective practices can flourish if the organisational context goes wrong. ${ }^{1-4}$ In such situations, it is vitally important that employees feel that they can speak out and raise concerns when they see poor quality care and/or unsafe practice. It is even more important that organisations respond positively to such concerns when they are raised, learn from any mistakes of the past, and put effective policies in place to prevent them from happening again. Unfortunately, there have been all-too-many high profile examples where serious concerns have been raised by front-line staff, but where these have not been adequately dealt with by the organisation. Patients have suffered as a result; and staff too may be harmed, from the direct and indirect consequences of their raising concerns.

Employee whistleblowing - loosely, the disclosure to a person or public body, outside normal channels and management structures, of information concerning unsafe, unethical or illegal practices - has emerged as a central issue in debates over quality and safety in many health systems. ${ }^{1}$ In the English National Health Service (NHS) for example, recent public inquiries and reports into poor standards of care have highlighted the vital role that employee whistleblowing can play in the detection and prevention of harm to patients ${ }^{2,5}$ : "When an NHS worker speaks up, they are making a vital contribution to the quality and safety of patient care. This is true not just for doctors, nurses, and other qualified healthcare professionals, but of all NHS workers regardless of position." 5 p 30.

But how can we understand such whistleblowing practices, and how can we place them in a proper organisational context?

Safe, or Sorry?

Whistleblowing policies have been mandated and promoted for many years-by healthcare employers, healthcare regulators and professional associations - aimed particularly at securing safe and effective services. Yet numerous surveys across different professional groups highlight a disconnect between whistleblowing policies in theory and how such arrangements work in practice. One possible reason for this is the widely held perception among health professionals that they will be victimised, ostracised or bullied if they raise legitimate concerns about the work of colleagues or about poor care.

For example, in the United Kingdom, the 2012 NHS staff survey found that although the majority of NHS staff (90\%) would know how to report any concerns they might have, only $72 \%$ reported that they would 'feel safe raising these concerns' and only just over half (55\%) reported that they would 'feel confident' that their organisation would address them. ${ }^{6}$ Moreover, in 2013 the Royal College of Nursing polled its members and almost a quarter (24\%) said that they had been 'warned off' or otherwise discouraged from whistleblowing. Furthermore, $45 \%$ in the same survey said that their employer 'took no action' even when they had spoken out.

Doctors are not immune from such concerns either: a survey of medical practitioners undertaken in 2012 by the Medical Protection Society (MPS) reported that just 11\% of respondents said they would be confident of the process if they blew the whistle, and $49 \%$ of doctors reported that 'fear of consequences' is why the whistleblowing process is ineffective. Indeed, only a third of doctors who had blown the whistle (33\%) said that their colleagues had supported their decision. $^{7}$

If whistleblowing is to be an effective part of any national strategy for better safer care, then staff need to feel not only that their concerns will be taken seriously, and acted upon, but that they personally will not be at risk.

\section{Heroes, or Villains?}

Individual whistleblowers may be perceived as heroes by some (for championing patients' interests; for promoting better care; for challenging management) but may be seen 
as villains by others (for stepping outside of usual proceses; for denigrating services; for damaging professional and organisational reputations). Indeed, within the literature and in the popular media, whistleblowers are often portrayed as either 'courageous employees', who act to maintain standards at great personal cost, or as 'disloyal malcontents', who 'snitch' or 'grass' on colleagues, and pursue their own interests regardless of the dysfunctional consequences for individuals and organizations. ${ }^{8}$ Beyond this, it would be naïve to assume that all whistleblowers are necessarily motivated entirely by genuine concerns about patient care: some may be motivated in addition by work grievances or personality clashes; concerns raised may even be of a malicious nature (probably rare, but certainly possible).

In fact, clear delineation between such labels is problematic. Whistleblowing arises out of complex and contested circumstances, and is attached to individuals with (often) complex personal and professional histories and (like all of us!) with certain personal idiosyncrasies. Binary distinctions (such as hero/villain; loyal/disloyal; warranted/unwarranted) are often unhelpful and disguise the complexity and ambiguity of whistleblowers and whistleblowing.

Distinguishing whether someone is 'a hero' or 'a trouble-maker' (or, more problematically, both) is fraught. Interpretation of the local service context, as well as of the personal history and attributes of the whistleblower in the light of whistleblowing actions, is likely to be shaped by prior knowledge, preferences and interests. Indeed, local discursive practices (eg, on the nature of success, failure, risk, and performance) and operational contingencies (such as resource constraints, service rivalries, stakeholder pressures, etc.) are likely to have a powerful shaping role. So too will power itself: who has the knowledge, status and position to be able to assert one narrative over another? Such assessments hinge less on 'facts' and more on discursive power; control over the narrative, managing ambiguity and handling contestation are likely to be central.

Whistleblowing then, is often fraught with rival interpretations and always happens in a deeply cultural and highly situated organisational context. Organisational policies thus need very careful design, implementation and enacting to protect those raising legitimate concerns as well as offering support in cases of fallout from more vexatious whistleblowing.

Cultures of Silence and Cultures of Voice in Healthcare Organisations

Policy prescriptions have tended to conceive the issue of raising concerns about unsafe or poor quality care as a simple (individual) choice between deciding to 'blow the whistle' or determining to remain silent. Yet research suggests that such simple dichotomies are unhelpful: for example, healthcare professionals may raise concerns internally within the organisation in more informal ways before (or instead of) utilising whistleblowing processes. ${ }^{9}$

Before coming to any decision on whether to blow the whistle, employees usually find themselves trying to work out exactly what is happening, often through engaging in dialogue with colleagues and seeking a 'second opinion.' Other informal strategies may include the use of humour or sarcasm to signal discontent, or the use of 'off-the-record' discussions with managers and employees. ${ }^{10}$ Sometimes this kind of behaviour is framed as a prelude to whistleblowing, and sometimes as a substitute.

This suggests that these informal and circumlocutory channels of communication may be valuable organisational mechanisms for addressing and preventing unsafe care (of course, they may also act as 'safety valves' for staff discontent without leading to any effective action). It also draws attention to the fact that the process of raising concerns about unsafe care may be largely hidden from view (apart from those participating directly in the dialogue) and may therefore not readily be identifiable as voicing concern, much less 'whistleblowing.' Such a view highlights the different routes through which healthcare employees are able to articulate their 'voice', and challenges the pejorative notion, often promoted in the media, that healthcare professionals are culpable bystanders who tolerate poor standards of care and are 'silent witnesses' to malpractice and mistreatment.

Silence or voice then is not a binary choice but more of a spectrum. It is also about more than just individuals: it is collective and cultural. Moreover, while 'organisational silence' - defined as 'the collective-level phenomena of doing or saying very little in response to significant problems or issues facing an organization ${ }^{11}$ - may be undesirable, it is not clear that whistleblowing is the necessary solution. We should look hard at how whistleblowing policies and practices contribute to the cultural aspects of voice and silence in the organisation setting.

\section{Hearing, Listening and Acting}

Effective voicing of concerns is but the first stage in reshaping better safer healthcare: those with influence have to hear, and they have to act. In the management literature, the concept of the 'deaf effect' has been defined as occurring when 'the decision-maker does not hear, ignores or overrules a report of bad news to continue a failing course of action.' ${ }^{12}$ A number of personal, social, and organisational factors have been identified which conspire to shape and sustain 'organisational deafness' in the face of poor and unsafe care ${ }^{13}$ Central to these are entrenched hierarchical status and power differences between different professional and occupational groups (eg, between nurses and doctors, or between frontline staff and managers) serving to limit or attenuate the development of open reporting cultures. ${ }^{8,14}$

It is not immediately clear how whistleblowing ameliorates rather than exacerbates the 'deaf effect' in organisations. After all: the more unpalatable the messages, the less likely the willingness of those concerned to really hear those messages and to act upon them. Any articulation of a whistleblowing strategy must deal with the challenging organisational dynamic of resistance to bad news, especially by those in positions of power who may already be vested in narratives of success. Just as whistleblowers' actions may be complex, variably motivated, ambiguous and contested, so too can be the responses of those in authority (within and outside the organisation) when confronted with new information and demands for action. While an unwillingness to hear and resistance to change are commonplace, other responses may be seen: from shifts in attitudes and understanding, to direct actions; from actions that support beneficial change to those 
that denigrate and damage the whistleblowers. Thus we need as sophisticated an understanding of these response dynamics as we do of the dynamics of whistleblowing itself.

\section{Concluding Remarks}

Healthcare scandals in many countries provide tangible evidence of the significant shortcomings in the protection and support offered to whistle-blowers even when they raise legitimate concerns: healthcare organisations frequently disregard such concerns and provide inadequate responses to the issues raised. In some cases, it is clear that senior players seek to ostracise and isolate individuals by undermining their concerns; in extreme cases, healthcare professionals have been disciplined, suspended or reported for misconduct to professional bodies on pretexts derived from a very particular and partisan reading and framing of events.

We would contend that much thinking about whistle blowing misconstrues it as something separate from normal organisational functioning, and so misses a broader opportunity to consider voice and silence in the round in organisational settings. Whistleblowing, in our view, sits as part of a wide spectrum of formal and informal behaviours that are embedded in local organisational context and cultures, ${ }^{15,16}$ and enmeshed in both formal and informal governance arrangements and practices. Central here is the ambiguity of judgements and practices that are shaped by clashing discourses, discourses that in turn are shaped by local interests and power relations.

Creating the right organisational environments where voices can be aired, divergent narratives can be acknowledged, and (even in the face of ambiguity) effective action aimed at better safer care can be enacted, remains the laudable, if elusive, goal. Whistleblowing can be a part of this, but it needs to be understood with due cognisance of the wider organisational setting, and not seen as something somehow separate and different, a 'bolt on' addition.

\section{Ethical issues}

Not applicable.

Competing interests

The authors declare that they have no competing interests.

Authors' contributions

RM and HTD contributed equally to the writing of this article.

\section{Authors' affiliations}

${ }^{1}$ Health Services Management Centre, University of Birmingham, Birmingham, UK. ${ }^{2}$ School of Management, University of St Andrews, Fife, UK.

\section{References}

1. Braithwaite J, Matsuyama Y, Mannion R, Johnson J. Healthcare Reform, Quality and Safety: Perspectives, Partnerships and Prospects in 30 Countries. Burlington, USA: Ashgate; 2015.

2. Francis R. The Mid Staffordshire NHS Foundation Trust Public Inquiry (Chaired by Robert Francis QC) Report of the Mid Staffordshire NHS Foundation Trust. London: HSMO; 2013.

3. Ohnishi R, Hayama Y, Kosugis S. An analysis of patient right violations in psychiatric hospitals in Japan after the enactment of the Mental Health Care act of 1987. Issues Ment Health Nurs. 2008;29(12):1290-1303. doi:10.1080/01612840802498417

4. Shearer B, Marshall, S Buist M, et al. What stops hospital clinical staff from following protocols? An analysis of the incidents and factors behind the failure of bedside clinical staff to initiate the rapid response system in a multi-campus Australian metropolitan healthcare service. BMJ Qual Saf. 2012;21(7):569575. doi:10.1136/bmjqs-2011-000692

5. Francis R. Freedom to Speak Up: An Independent Review into Creating an Open and Honest Reporting Culture in the NHS. London: The Stationery Office; 2014.

6. NHS Staff Survey (NSS) 2012. London: Department of Health; 2012.

7. Medical Protection Society (MPS). Whistleblowing Doctors Afraid to Speak out. London: MPS; 2012.

8. Jones A, Kelly D. Whistle-blowing and workplace culture in older peoples' care: qualitative insights from the healthcare and social care workforce. Sociol Health IIIn. 2014;36:986-1002. doi:10.1111/1467-9566.12137

9. Blenkinsopp J, Edwards MS. On not blowing the whistle: quiescent silence as anemotion episode. In: Zerbe WJ, Härtel CE, Ashkanasy NM, eds. Emotions, Ethics, and Decisionmaking. Bingley, United Kingdom: Emerald Group Publishing; 2008:181-206

10. Kelly D, Jones A. When care is needed: the role of whisteblowing in promoting best standards from an individual and organizational perspective. Qual Ageing Older Adults. 2013;14(3):180-191. doi:10.1108/QAOA-05-2013-0010

11. Henriksen K, Dayton E. Organisational silence and threats to patient safety. Health Serv Res 2006;41(4):1539-1554. doi:10.1111/j.1475-6773.2006.00564.x

12. Cueller M. An investigation of the Deaf effect response to bad news reporting in information systems projects. Georgia State University. Accessed May 10. 2015. Published 2009.

13. Davies HT, Mannion R. Will prescriptions for cultural change improve the NHS? BMJ. 2013;346:f15. doi:10.1136/bmj.f1305

14. Mannion R, Thompson C. Systematic biases in group decisionmaking: implications for patient safety. Int J Qual Health Care. 2014;26(6):606-612. doi:10.1093/intqhc/mzu083

15. Mannion R, Davies H, Marshall M. Cultures for Performance in Healthcare, Buckingham: Open University Press; 2005.

16. Mannion $\mathrm{R}$, Davies $\mathrm{H}$, Marshall $\mathrm{M}$. Cultural attributes of 'high' and 'low' performing hospitals. J Health Organ Manag 2005;19(6):431-439. doi:10.1108/14777260510629689 